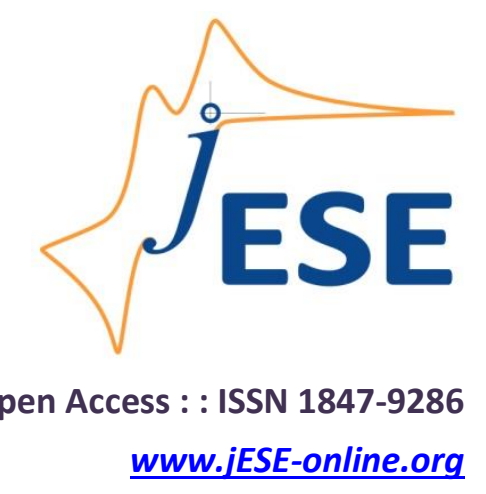

Short communication

\title{
Electrochemical immunosensor for the determination of $\beta$-casein
}

\author{
Judith Molinari, Carlos Moina and Gabriel Ybarra ${ }^{凶}$ \\ Unidad Técnica Nanomateriales, INTI-Procesos Superficiales, Instituto Nacional de Tecnología \\ Industrial, C.C. 157, B1650WAB San Martín, Argentina
}

${ }^{\square}$ Corresponding Author: E-mail: gabriel@inti.gov.ar; Tel.: 011-4724-6333; Fax: 011-4724-6343

Received: October 6, 2014; Revised: February 20, 2015; Published: March 15, 2015

\begin{abstract}
An amperometric biosensor for the quantification of food allergens based on an inhibitory immunoassay is presented. As a proof of concept, the experimental conditions were optimized for the detection of $\beta$-casein in the 0-10 ppm range. Eight electrochemical cells were integrated into a small-sized portable potentiostat controlled by a smartphone via Bluetooth communication. The determination of $\beta$-casein in eight different samples can be measured with the electrochemical biosensor, which has the potential to be modified for the detection of multiple allergens.
\end{abstract}

\section{Keywords}

Allergen; Casein; Electrochemistry; ELISA; Immunoassay

\section{Introduction}

Food allergies are a worldwide growing concern due to its impact on food safety and public health. Milk is one of the most common food allergens affecting infants, with prevalence roughly between $1 \%$ and $15 \%$ [1]. Milk contains several proteins that can be potentially involved in allergic sensitization but only a few of them are recognized as being major allergens, mainly $\beta$ lactoglobulin, caseins, and $\alpha$-lactalbumin. There are several technical possibilities for the detection of milk allergenic proteins, targeting either the protein itself or DNA fragments [Schubert-Ullrich et al. 2009]. ELISA is the most commonly used method in food industry laboratories due to its high precision, low detection limits, and high specificity. However, ELISA's drawbacks include its timeconsuming procedure and the requirement of relatively expensive laboratory instrumentation.

Biosensors are compact analytical devices which employ specific biorecognition elements combined with state-of-the-art integrated electronics, and represent an inexpensive alternative to 
methods which require desktop instrumentation such the enzyme-linked immunosorbent assay (ELISA) [3,4]. Biosensors are characterized by their portability, ease of use and high degree of automation, ideally maintaining high quality analytical standards. Although a considerable amount of work in the field of biosensors has been carried out in recent years, the use of electrochemical biosensors aimed at the detection of food allergens is rather scarce. A recent review presents an up-to-date outlook of the field [5]. Competitive ELISA biosensors have been developed for the detection of cyanobacterial toxins [6] and okadaic acid in shellfish [7]. Most of the electrochemical biosensors for the detection of food allergens are based on transduction techniques such as differential pulse voltammetry and electrochemical impedance spectroscopy. Low limits of detections (in the order of $\mathrm{nM}$ or $\mathrm{ng} \mathrm{m}^{-1}$ ) have been reported using these techniques $[8,9]$. However, these techniques require a rather complex electronic instrumentation. Moreover, in many cases of practical interest the most useful range of concentration of food allergens lies in the order of 1-10 ppm $[10,11]$.

Here we present the preliminary results of an alternative method for the detection of $\beta$-casein in the order of a few ppm consisting in a portable immunosensor devised for the analysis of food allergens. It is based on antigen-antibody reactions between soluble and immobilized antigens. Antigen-antibody complexes formed onto the electrode surface are detected with a redox enzyme-labeled secondary antibody. The enzymatic activity is amperometrically detected after the application of a potential step so that the associated electronics are simple and data processing is straightforward. Moreover, Bluetooth connectivity and a smartphone application make possible to carry out quantitative measurements with this portable, compact and easy-to-use device, without the need of computers.

\section{Experimental}

N-hydroxysuccinimide (NHS), 1-ethyl-3-(3-dimethylaminopropyl)carbodiimide (EDC), type I horseradish peroxidase (HRP) and $\beta$-casein from bovine milk were purchased from Sigma-Aldrich. Rabbit polyclonal antibody anti-(bovine $\beta$-casein) was provided from the Biochemistry and Nutrition Area, Institute of Food Technology, Agrobusiness Research Centre, National Institute of Agricultural Technology. Goat anti-rabbit IgG $(\mathrm{H}+\mathrm{L})$-HRP conjugate was purchased from Biorad. Phosphate buffer saline pH 7.2-7.5 (PBS) was prepared with $0.1 \mathrm{M} \mathrm{NaH}_{2} \mathrm{PO}_{4}$ (Mallinckrodt) and $0.15 \mathrm{M} \mathrm{NaCl}$ (Biopack). Phosphate buffer $0.1 \mathrm{M} \mathrm{pH} 7.0$ was prepared with $\mathrm{KH}_{2} \mathrm{PO}_{4}$ (Merck). Blocking buffer was prepared with $0.01 \%$ polysorbate 20 (Biopack), $1 \%$ gelatin (Merck) in $0.1 \mathrm{M}$ buffer phosphate of $\mathrm{pH}$ 7.0. Rinsing buffer was prepared with $0.05 \%$ polysorbate 20 (Biopack ${ }^{\circledR}$ ) in $0.1 \mathrm{M}$ buffer phosphate of $\mathrm{pH}$ 7.0. Measurement buffer was prepared in PBS with $0.1 \mathrm{M} \mathrm{KCl}, 4 \mathrm{mM}$ hydroquinone and $1.5 \mathrm{mM}$ hydrogen peroxide (Biopack).

Thick film carbon electrodes were printed onto $\alpha-\mathrm{Al}_{2} \mathrm{O}_{3}$ substrates by screen printing technology (Fig. 1a). A commercial carbon paste (Dupont BQ242) and $96 \% \alpha-\mathrm{Al}_{2} \mathrm{O}_{3}$ substrates were employed. Electrode layout was transferred by means of photolithography to a stainless steel mesh (200 wires per inch) with a negative photosensitive film (Ulano CDF-4). Carbon ink printing was performed with an EKRA Microtronic-II printer, dried in box oven at $70{ }^{\circ} \mathrm{C}$ during 20 min. The electrodes were integrated in an electrochemical cell, constructed with poly(methylmethacrylate) (PMMA) using a numeric control device from a CAD layout (Fig. 1c). The carbon electrodes were treated with an oxygen plasma to promote the formation of carboxylic groups on the surface. A Diener plasma polymerization equipment was used under following conditions: an oxygen pressure of $1 \mathrm{mbar}$, a set temperature of $50^{\circ} \mathrm{C}$ and a time of plasma treatment of $15 \mathrm{~s}$. 
a

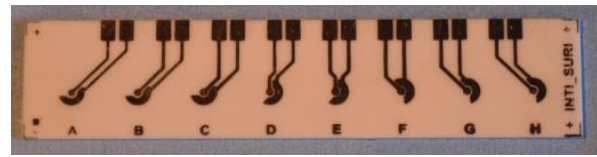

b
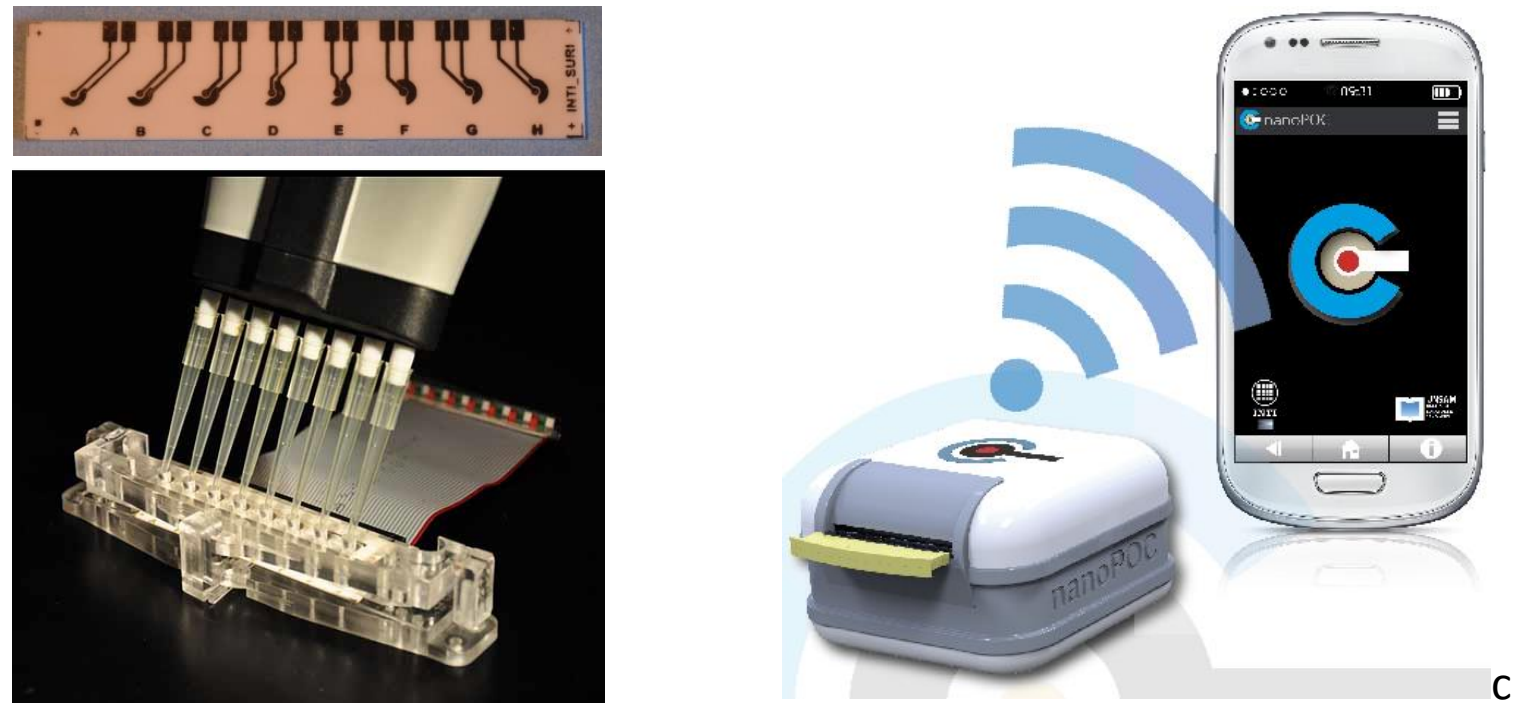

Figure 1. (a) Set of 8 pairs of working and counter electrodes screen printed on alumina;

(b) electrochemical cells; (c) electrochemical platform comprehending electrochemical cells and electronic instrumentation connected to a smartphone via Bluetooth.

$\beta$-casein was immobilized onto the electrode surface using the carbodiimide method [12]. Carboxylic groups formed on the carbon electrode after plasma treatment were treated with $100 \mu \mathrm{l}$ of $0.1 \mathrm{M} \mathrm{EDC}$ and $10 \mu \mathrm{l}$ of $25 \mathrm{mM}$ NHS for 30 minutes and, after rinsing, incubated for 2 hours with $50 \mu \mathrm{l}$ of a $100 \mathrm{ppm} \beta$-casein solution in $0.1 \mathrm{M}$ phosphate buffer of $\mathrm{pH}$ 7.0. After rinsing, the electrodes were incubated overnight at $4{ }^{\circ} \mathrm{C}$ in a wet chamber with the blocking buffer. Finally, the electrodes were rinsed and were ready to be used. Solutions of $\beta$-casein in PBS of different concentrations $(0,1,5,10,15$ and $20 \mathrm{ppm})$ and 1:10000 rabbit polyclonal antibody antibovine $\beta$-casein in blocking buffer solution (1:1) were pre-incubated and added to each electrode for 1 hour at $37^{\circ} \mathrm{C}$. Rinsed electrodes were incubated with 1:2000 goat anti-rabbit IgG conjugate blocking buffer solution in same conditions.

Potentials were measured and referred to in the text against an $\mathrm{Ag}|\mathrm{AgCl}| 0.1 \mathrm{M} \mathrm{KCl}$ reference electrode $(\varnothing 1 \mathrm{~mm})$. Electrochemical measurements were carried out at $25^{\circ} \mathrm{C}$ in $50 \mu \mathrm{l}$ of a PBS buffer of $\mathrm{pH} 7,0.1 \mathrm{M} \mathrm{KCl}, 4 \mathrm{mM}$ hydroquinone (redox mediator) and $1.5 \mathrm{mM} \mathrm{H}_{2} \mathrm{O}_{2}$, prepared from analytical grade reagents (Merck) and mili-Q water. Amperometric measurements were carried out with a portable potentiostat Nanopoc ${ }^{\circledR}$ controlled by a smartphone via Bluetooth connection, schematically shown in Fig. 1c. Details on the electronic instrumentation are given elsewhere [13]. The working electrode potential was set at $-280 \mathrm{mV}$ and the resulting current was recorded during $60 \mathrm{~s}$; this potential value is negative enough to produce the reduction of 1,4 benzoquinone under diffusion-controlled conditions [14].

The concentration of $\beta$-casein used for the immobilization, the dilutions of the primary and secondary antibodies and the incubation parameters were optimized by ELISA based on a protocol developed by Vitkova et al. [15]. The optimized values found for ELISA were tested on the biosensor and the electrochemical signal was optimized again adjusting the dilution of the primary and secondary antibodies. The polystyrene microplates were filled with different concentration of $\beta$-casein $(0,2.5,10$ and $100 \mathrm{ppm})$ in carbonate-bicarbonate buffer of pH $9.6(50 \mu \mathrm{l} /$ well) and incubated overnight at $4{ }^{\circ} \mathrm{C}$ for absorption. The coated plates were washed three times with 0.01 M PBS containing $0.01 \%$ polysorbate 20 (PBS-P20) to remove unbound antigens. Each well was filled with $300 \mu \mathrm{l}$ of blocking buffer (PBS-P20 containing $1 \%$ gelatin) for 1 hour at room 
temperature and was washed three times with PBS-P20. $55 \mu \mathrm{l}$ of PBS-P20 containing different concentrations of $\beta$-casein $(0,0.1,10,100 \mathrm{ppm})$ and $55 \mu \mathrm{l}$ of different dilutions in PBS-P20 $1 \%$ gelatin $(1: 10000,1: 128000,1: 1000000)$ of the primary antibody (rabbit polyclonal antibody antibovine $\beta$-casein) were pre-incubated during $1 \mathrm{~h}$ at $37^{\circ} \mathrm{C}$. Aliquots $(90 \mu \mathrm{l})$ from the content of each preincubated well were incubated with immobilized $\beta$-casein during $1 \mathrm{~h}$ at $37^{\circ} \mathrm{C}$. After washing three times with PBS-P20, $100 \mu$ l of the HRP conjugate secondary antibody (goat anti-rabbit IgG (H + L)-HRP conjugate) diluted 1:5000 in PBS-P20 $1 \%$ gelatin were added to each well, incubated for $1 \mathrm{~h}$ at $37^{\circ} \mathrm{C}$, washed three times with PBS-P20. Aliquots $(50 \mu \mathrm{l} /$ well) of $50 \mathrm{mM}$ citrate/phosphate buffer of $\mathrm{pH} 3.2$ containing $60 \mathrm{mM}$ hydrogen peroxide and $50 \mu \mathrm{l} /$ well TMB $\left(3,3^{\prime}, 5,5^{\prime}\right.$ tetramethylbenzidine $0.01 \mathrm{M}$ ) in $0.1 \mathrm{~N} \mathrm{HCl}$ were incubated during $30 \mathrm{~min}$ at room temperature. The reaction was stopped with $50 \mu \mathrm{l} /$ well of $2 \mathrm{M} \mathrm{H}_{2} \mathrm{SO}_{4}$. Absorbance was measured at $450 \mathrm{~nm}$.

In brief, the tested values of concentration of $\beta$-casein used in the immobilization on polystyrene wells were $0,2.5,10$ and $100 \mathrm{ppm}$. The used primary antibody dilutions were 1:10000, $1: 128000$ and 1:1000000 while the dilution of the secondary antibody was kept constant at 1:5000, following the recommendations given by the supplier. The best results for ELISA were obtained when a solution of $100 \mathrm{ppm} \beta$-casein used for the immobilization on polystyrene, with 1:128000 and 1:5000 dilutions for the primary and secondary antibodies respectively. When the optimized values found for ELISA were used in the electrochemical biosensor, it was found that higher antibody titers were necessary; consequently a 1:10000 and 1:2000 dilutions were used for the primary and secondary antibodies, respectively.

\section{Results and discussion}

The biosensor presented here is a portable immunosensor devised for food allergen analysis. The allergen of choice was $\beta$-casein, one of the main milk proteins. This method is based in inhibitory antigen-antibody reactions between soluble and electrode surface immobilized antigen. The electrochemical signal detected, due to the enzymatic activity of HRP-conjugated secondary antibody, is inversely related to the $\beta$-casein concentration in the sample solutions.

Carbon screen printed electrodes were used because of their low cost and ease of preparation. The central working electrode has a diameter of $1 \mathrm{~mm}$. A set of 8 pairs of working electrodes and counter electrodes were printed to fit an acrylic cell with a total volume of $50 \mu$ l. The carbon electrodes were treated with an oxygen plasma which is known to generate carboxylic groups in the carbon surface [16]. The carboxylic groups were used as anchoring sites for proteins, either HRP or $\beta$-casein, through the carbodiimide reaction.

\section{Enzymatic electrodes}

In order to assess the performance of the chosen immobilization procedure, HRP enzymes were immobilized onto the plasma-treated carbon screen printed electrodes. Fig. 2a shows the current transients obtained for concentrations of hydrogen peroxide in the 0-3 $\mathrm{mM}$ range. The measured current increases with increasing hydrogen peroxide concentration. A plot of the current measured at $60 \mathrm{~s}$ versus the hydrogen peroxide concentration is shown in Fig. $2 \mathrm{~b}$. 

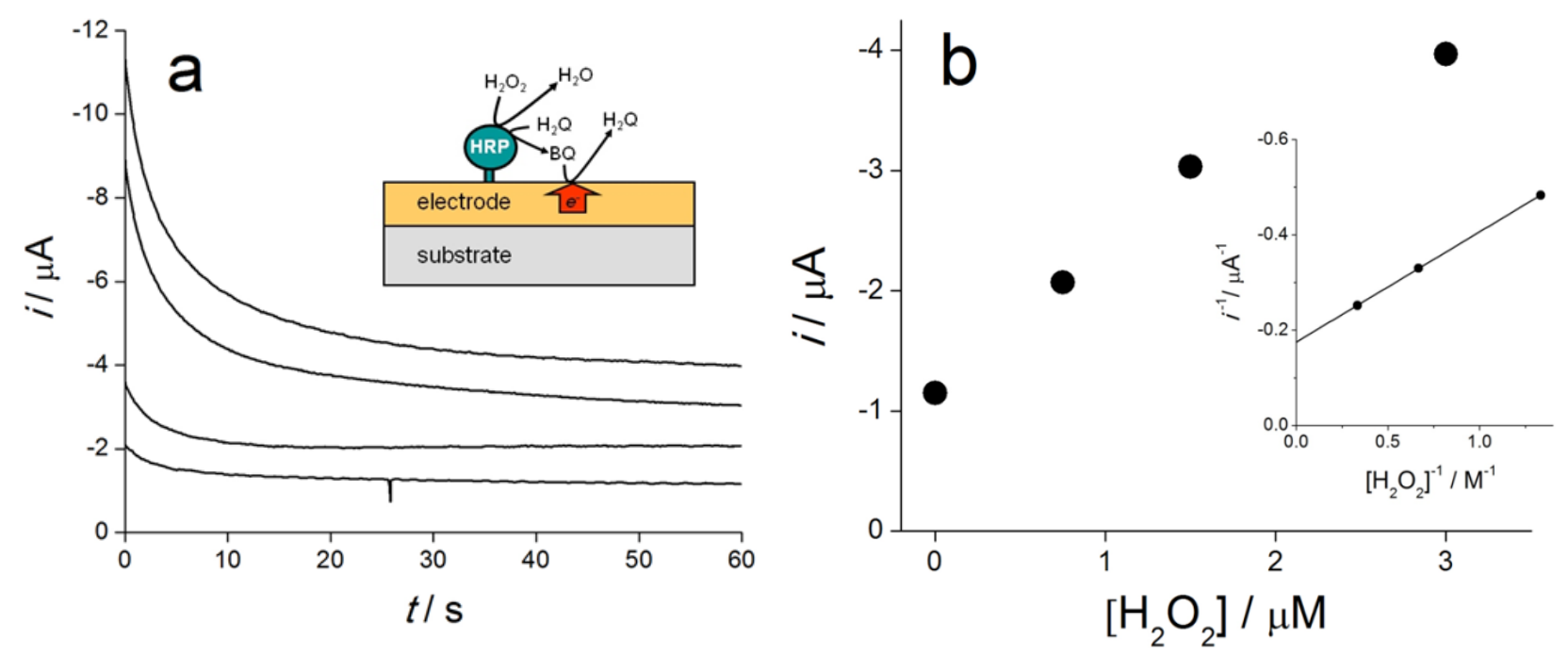

Figure 2. Electrochemical detection of the enzymatic activity of HRP immobilized onto the carbon working electrode. (a) Current transients obtained at an applied electrode potential of -0.280 V for $\mathrm{H}_{2} \mathrm{O}_{2}$ concentrations between 0 and $3 \mathrm{mM}$ (from top to bottom: 3, 1.5, 0.75 and $0 \mathrm{mM}$ ); (b) Dependence of the current measured at $60 \mathrm{~s}$ with the peroxide concentration. Inset: Lineweaver-Burk plot.

The measured current can be related to the rate of reaction. The catalyzed reduction of peroxide can be expressed as:

$$
\mathrm{H}_{2} \mathrm{O}_{2}+\mathrm{H}_{2} \mathrm{Q} \rightarrow 2 \mathrm{H}_{2} \mathrm{O}+\mathrm{BQ}
$$

where $\mathrm{H}_{2} \mathrm{Q}$ and $\mathrm{BQ}$ stands for hydroquinone and 1,4-benzoquinone respectively. On the other hand, a fraction $f$ of the total of the 1,4-benzoquinone produced in the catalytic reaction is reduced back into hydroquinone at the electrode surface:

$$
\mathrm{BQ}+2 \mathrm{H}^{+}+2 e^{-} \rightarrow \mathrm{H}_{2} \mathrm{Q}
$$

Considering that the consumption of $n$ moles of hydrogen peroxide will generate the circulation of a charge equal to $2 f F n$, where $F$ is the Faraday constant, it follows that the reaction rate (v) of peroxide consumption is related to the current by the stoichiometry of the reactions and the collection factor $f$ by the following equation:

$$
v / \mathrm{mol} \mathrm{s}^{-1}=\frac{i}{2 f F}
$$

For enzymatic catalyzed processes, the relationship between the reaction rate and the concentration of the substrate $\left(\left[\mathrm{H}_{2} \mathrm{O}_{2}\right]\right)$ is given by the Michaelis-Menten equation [28]:

$$
v=\frac{v_{\max }\left[\mathrm{H}_{2} \mathrm{O}_{2}\right]}{K_{\mathrm{M}}+\left[\mathrm{H}_{2} \mathrm{O}_{2}\right]}
$$

where $v_{\max }$ is the maximum rate and $K_{\mathrm{M}}$ is the Michalis-Menten constant. The values of $v_{\max }$ and $K_{\mathrm{M}}$ can be obtained from the slope and the intercept of a linearized Lineweaver-Burk plot, $1 / v$ vs. $1 /\left[\mathrm{H}_{2} \mathrm{O}_{2}\right]$ :

$$
\frac{1}{v}=\frac{K_{\mathrm{M}}}{v_{\max }} \frac{1}{\left[\mathrm{H}_{2} \mathrm{O}_{2}\right]}+\frac{1}{v_{\max }}
$$


Assuming a collection efficiency of $100 \%$ (i.e. $f=1$ ), reproducible values of around $1.3 \mathrm{mM}$ have be estimated for $K_{M}$ from Lineweaver-Burk plots such as the one shown in the inset of Fig. $2 b$. This value for $K_{\mathrm{M}}$ is not far from others reported for HRP immobilized onto surfaces (e.g, $0.65 \mathrm{mM}$ in [17]). Although the actual value of the collection factor is not known, the reproducibility of the kinetic curves for different electrodes suggests that a stable architecture of the enzymatic electrode is attained so that the collection factor has a constant value.

In brief, these results show that the enzymes immobilized onto plasma-treated carbon electrodes exhibit a high catalytic activity, which can be explained in terms of a Michales-Menten kinetics [Chang and Tang 2014], and that the enzymatic electrode are suitable for quantitative measurements.
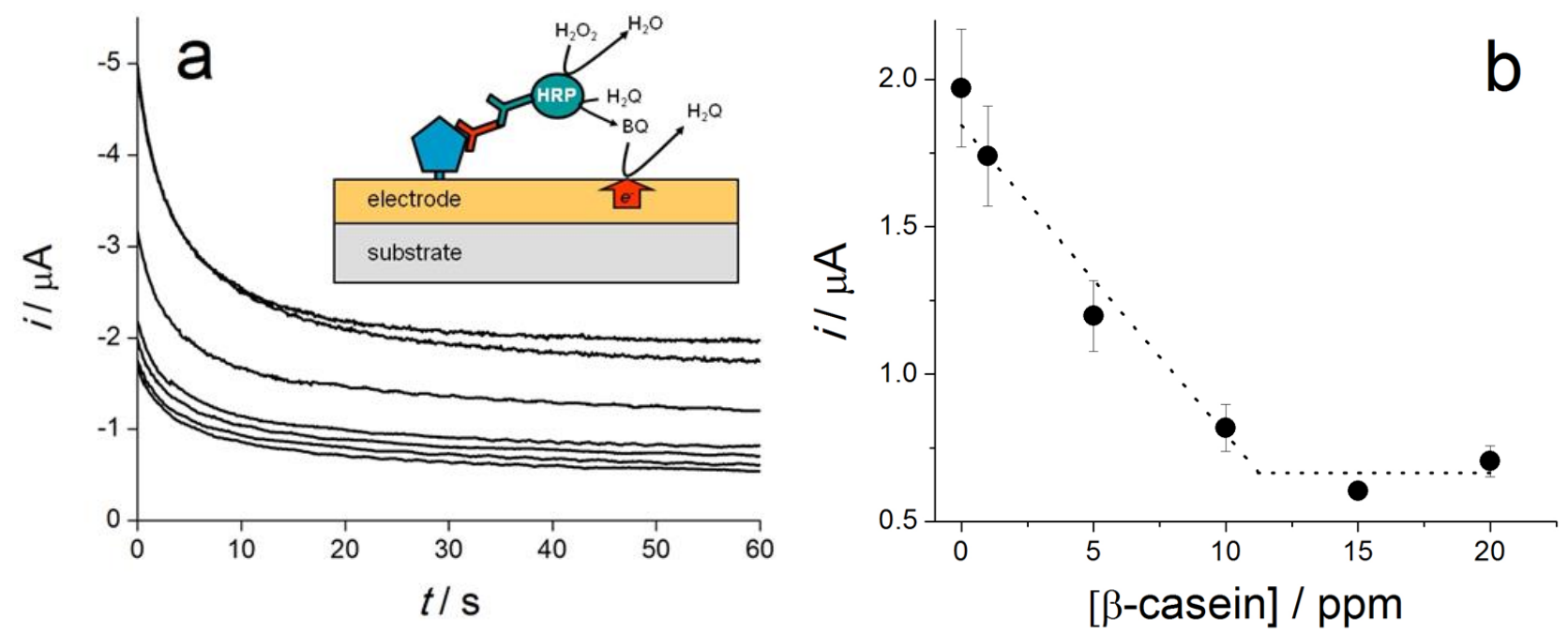

Figure 3. Electrochemical determination of $\beta$-casein: (a) Current-time curves obtained at an applied electrode potential of $-0.280 \mathrm{~V}$ at a $\mathrm{H}_{2} \mathrm{O}_{2}$ concentration of $1.5 \mathrm{mM}$ with different $\beta$-casein concentration in the sample (from top to bottom: $0,1,5,10,15$ and $20 \mathrm{ppm}$, and blocking buffer),

(b) Dependence of the current measured at $60 \mathrm{~s}$ on the $\beta$-casein concentration. Error bars were calculated as the standard deviation of three independent experiments.

\section{Immunoenzimatic determination of $\beta$-casein}

The determination of $\beta$-casein is based on an inhibitory immunoassay. Firstly, rabbit Ig anti- $\beta$ casein antibodies were incubated with the sample and then transferred into the electrochemical cell which contained the electrode with immobilized $\beta$-casein. Depending on the concentration of $\beta$-casein present in the sample, a quantity of free anti- $\beta$-casein antibodies could still be available to bond to the immobilized $\beta$-casein. Those bonded antibodies are detected with a HRPconjugated secondary antibody. Finally, the enzymatic activity is amperometrically detected by adding hydrogen peroxide and a suitable redox mediator at an electrode potential negative enough to produce the reduction of the redox mediator (Fig. 3a). Under these conditions, the concentration of $\beta$-casein could be inversely related to the measured current as shown in Fig. $3 \mathrm{~b}$.

Most countries have not established regulations on the maximum allowed content of allergens in food. In this regard, the Japanese Food Sanitation Law, dated 2001 and amended in 2008, is one of the few available regulations, in which a maximum concentration of $10 \mathrm{ppm}$ was established taking into account that traces of allergens can lead to allergic reactions [11]. Considering the Japanese regulation as a valid reference, the conditions were optimized to obtain a standard curve for the detection of $\beta$-casein in the $0-10$ ppm range (Fig. 3b). 
This measurement range is useful for allergen monitoring in food industry activities and this portable equipment represent an important advantage as compared to commercial analytical methods in terms of costs and portability.

\section{Conclusions}

The determination of food allergens is a subject of increasing concern. The development of an amperometric electrochemical biosensor associated with an inhibitory immunoassay presented in this work for the detection of food allergens has several advantages. The immunoassay has been optimized for the $0-10 \mathrm{ppm}$ range, which is the most relevant according to health regulations. The chosen electrochemical transduction technique used in the presented biosensor was amperemetry, which is the least regarding in terms of electronic instrumentation and data treatment. Furthermore, the set of 8-electrochemical cells has been designed to fit a portable potentiostat, which can be connected to a smartphone or tablet via Bluetooth connectivity and can be used for analyzing different analytes at the same time. The biosensor has been designed for the determination of $\beta$-casein and can be properly modified for the detection of other allergens.

Acknowledgements: This work has been supported by the Instituto Nacional de Tecnología Industrial and by FS Nano 2010/05 "Nanopoc" granted by the Ministry of Science, Technology and Innovative Production of the Argentine Republic. The authors thank Mijal Mass and Mariano Roberti from INTI-CMNB for the design and preparation of thick film electrodes and the acrylic electrochemical cell, Anahí Medrano from INTI-CMNB for plasma treatments, Vanina Ambrosi and Gustavo Polenta from the Laboratorio de Compuestos Protéicos of the Instituto Nacional de Tecnología Agropecuaria for kindly providing proteic compounds and Marcela Pagano and Estela Faulkes from the Immunoserology Section of the Instituto de Investigaciones Médicas "Alfredo Lanari".

\section{References}

[1] A. Fiocchi, J. Brozek, H. Schünemann, S. L. Bahna, A. von Berg, K. Beyer, M. Bozzola, J. Bradsher, E. Compalati, M. Ebisawa, M. A. Guzman, H. Li, R. G. Heine, P. Keith, G. Lack, M. Landi, A. Martelli, F. Rancé, H. Sampson, A. Stein, L. Terracciano, S. Vieths., Pediatr. Allergy Immunol. 21 (2010) 1-125.

[2] P. Schubert-Ullrich, J. Rudolf, P. Ansari, B. Galler, M. Führer, A. Molinelli, S. Baumgartner, Anal. Bioanal. Chem. 395 (2009) 69-81.

[3] G. Longinotti, G. Ybarra, P. Lloret, C. Moina, A. Ciochinni, D. Rey Serantes, L. Malatto, M. Roberti, S. Tropea, L. Fraigi, Engineering in Medicine and Biology Society, Annual International Conference of the IEEE, Buenos Aires, Argentina, 2010, 674-676.

[4] C. Moina, G. Ybarra, "Fundamentals and applications of immunosensors" in "Advances in Immunoassay Technology", InTech, Zagreb, Croatia, 2012.

[5] R. Pilolli, L. Monaci, A. Visconti, Trends Anal. Chem. 47 (2013) 12-26.

[6] M. Campàs, J.-L. Marty, Biosens. Bioelectron. 22 (2007) 1034-1040.

[7] M. Campàs, P. de la Iglesia, M. Le Berre, M. Kane, J. Diogène, J.-L. Marty, Biosens. Bioelectron. 24 (2008) 716-722.

[8] M. Saito, M. Kitsunai, M. Ahmed, S. Sugiyama, E. Electrochem. 76 (2008) 606-609.

[9] S. Eissa, C. Tlili, L. L'Hocine, M. Zourob, Biosens. Bioelectron. 38 (2012) 308-313.

[10] R. Pedreschi, J. Nørgaard, A. Maquet, Nutrients 4 (2012) 132-150.

[11] H. Akiyama, T. Imai, M. Ebisawa, Adv. Food Nutr. Res. 62 (2011) 139-171.

[12] F. Kurzer, K. Douraghi-Zadeh, Chem. Rev. 67 (1967) 107. 
[13] F. Salomón, G. Longinotti, G. Ybarra, P. Lloret, C. Moina, L. Malatto, M. Roberti, S. Tropea, L. Fraigi, M. Lloret, M. Mass, IEEE $9^{\text {th }}$ Ibero-American Congress on Sensors, Bogotá, Colombia, 2014, 1-4.

[14] P. Lloret, G. Longinotti, G. Ybarra, L. Socolovsky, C. Moina, Mat. Res. Bull. 48 (2013) 36713676.

[15] M. Vitkova, P. Rauch, L. Fukal, Czech J. Food Sci. 20 (2002) 53-62.

[16] E. De Las Heras, G. Ybarra, I. Bracera, P. Corengia, Surface modification by plasma-based processes in Functional Properties of Biological Surfaces: Characterization and Technological Applications, E. Favret, N. O. Fuentes Eds., World Scientific Publishing Co., New Jersey, U.S.A., 2009, p. 343-378

[17] Q. Chang, H. Tang, Molecules 19 (2014) 15768-15782.

(C) 2015 by the authors; licensee IAPC, Zagreb, Croatia. This article is an open-access article distributed under the terms and conditions of the Creative Commons Attribution license (http://creativecommons.org/licenses/by/4.0/) (cc) EY 